\title{
ВНУТРЕННИЕ И ВНЕШНИЕ ДЕТЕРМИНАНТЫ РАЗВИТИЯ ФОНДОВОГО РЫНКА
}

\author{
(c) 2020 Михайлов Александр Михайлович \\ доктор экономических наук, профессор кафедры «Экономическая теория» \\ Самарский государственный экономический университет (СГЭУ), Россия, Самара \\ E-mail:2427994@mail.ru
}

\section{(c) 2020 Петров Никита Анатольевич}

кандидат экономических наук, доцент кафедры «Экономическая теория» Самарский государственный экономический университет (СГЭУ), Россия, Самара

E-mail: petrovnikitamail@yandex.ru

В статье представлен обобщающий перечень факторов, способствующих развитию национального фондового рынка. С помощью эмпирических методов исследования определены и решены задачи выявления внутренних и внешних детерминант, определяющих доходность операций с ценными бумагами. Указаны последние тенденции в развитии торговых операций на фондовых площадках.

Ключевые слова: биржа, брокер, инвестиционная компания, инфляция, маржа, прибыль, располагаемый доход, ставка процента, финансовый актив, фондовый рынок.

Практически все из существующих макроэкономических факторов, оказывающих воздействие на динамику финансовых рынков, в том числе фондового, предполагают определение степени воздействия на доходность сводных финансовых индексов и определение способов их нивелирования. К числу подобных факторов следует относить процентную ставку, инфляцию, объем и динамику денежной массы, объем эмиссии денежных средств, фондовые индексы, цены на биржевые товары, динамику валютных курсов.

Изменения в ожидании инвесторов, связанные с определенными изменениями макроэкономических показателей, приводят к изменению цен [1]. На данный момент времени существует довольно много теоретических обоснований оказания влияния ставок процента на доходность ценных бумаг, и опосредованно на агрегированный фондовый индекс. Среди таковых:

- Ставка процента может показать предельную производительность капитала: невысокая процентная ставка отразит невысокую производительность капитала. Это может стать причиной формирования отрицательного расположения инвесторов к определенному ряду финансовых активов и уменьшению спроса на них, что, в итоге, будет способствовать уменьшению цены.
- Ставки процента показывают размер, скорость и частоту произведенных заимствований. Невысокий размер ставки процента предоставляет возможность компании уплачивать меньшую стоимость кредита и повышать свою операционную прибыль. Невысокие ставки процента выгодны для компаний, поскольку дают более выгодные условия для получения кредита и осуществления инвестирования в новые проекты. Также, низкие процентные ставки расширяют потребление, кредитование становятся более приемлемыми для физических лиц. Вследствие положительного воздействия низких процентных ставок, происходит рост ожиданий относительно дохода компаний, что приводит к росту цен на акции.

Однако, рост ставки процента снижает инвестиционную привлекательность акций. Инвесторы могут получить более высокую прибыль, осуществляя вложения в государственные облигации, являющиеся активами с меньшим риском. Большая часть покупок на фондовом рынке делается с учетом получения положительной маржи [2]. Принимая решение, инвестор учитывает стоимость ценных бумаг и стоимость сделок.

Другим, не менее важным показателем, оказывающим влияние на динамику сводных индексов фондового рынка, является инфляции. В тоже время влияние данного фактора на финан- 
совые показатели не однозначно.

Инвесторы могут рассматривать ценные бумаги как инструмент хеджирования. Если большое количество инвесторов начнет инвестировать в акции, как способ застраховаться от увеличения инфляции, то спрос на них вырастет и цены повысятся. Здесь следует упомянуть, что в работе Т.Энгстеда были получены результаты, говорящие о том, что ряд ценных бумаг, в том числе акции, не могут служить инструментом хеджирования [14]. Так, например, в долгосрочном периоде выявлено, что взаимосвязь доходности корпоративных облигаций с предполагаемыми темпами инфляции не имеет большой значимости.

Фельдштайн М. предложил определять показатель инфляции так: первый вариант, в виде налога на выручку фирм и как объясняющую категорию, уменьшающую показатель реальной амортизации [15]. В случае изучения, так называемой, нулевой инфляции, а впоследствии проведения ее сравнения со случаем ненулевой инфляции, по мнению М.Фельдштайна, возможно предположить вывод об уменьшении показателя реальной амортизации при увеличении ценовых характеристик. Этот случай способен увеличить размер налогооблагаемой базы и понизить показатель реальной прибыли, также и на одну единицу ценной бумаги, в частности на акцию.

Влияние инфляции, оказываемое на спрос по ценным бумагам, от которого в значительной степени зависит их цена, является зависимым от размера ставок налога на индивидуальную и корпоративную доходность.

Полностью экстраполировать методологические подходы зарубежных исследований к реалиям российского рынка ценных бумаг нельзя - недолгое существование и незначительная инвестиционная привлекательность не позволяет применять ряд ключевых критериев, описываемых в зарубежных научных работах [4]. Среди исследований, посвященных доходности российских ценных бумаг, в частности корпоративных облигаций, отметим труд Н.И. Берзона и Т.М.Милицковой. В работе указанных авторов изучены специфические параметры: цена на нефть, курс валют, влияние которых характерно именно для российской специфики доходности [3].

Процесс глобализации, характерный для текущей мировой экономической системы допустил то, что фондовые площадки разных го- сударств оказываются тесно пересечены друг с другом. Фондовые площадки США оказывают сильное воздействие на развивающиеся экономики. Считается, что фондовые площадки отражают состояние национальной экономики [9]. Развитые экономические системы оказывают влияние на менее развитие экономики, так и фондовый рынок развитых экономик во многом определяет степень колебаний на фондовых рынках развивающихся стран. Так, в работе Хайо Б. эмпирическое исследование указало, что американские фондовые индексы являются причинными по отношению к российским индексам РТС, Московской биржи [16].

Важной проблемой, все чаще проявляемой на финансовых рынках, фондовом в частности, является невысокие показатели эффективности отрасли финансового посредничества. Данные аспекты финансовых рынков объясняются существующей раздробленностью кредитно-финансовой системы, а также значительной степенью концентрации финансовых активов на разных участках рынка ценных бумаг. Для имеющихся видов институтов финансового рынка характерна следующая закономерность: финансовые активы 12-17\% организаций определенных сегментов рынка сосредоточены примерно в 87\% общих агрегированных финансовых активов.

Обращая внимание на достаточно большое количество действующих ныне финансовых посредников на рынке ценных бумаг, можно сказать, что для всех секторов фондового рынка наблюдается усиление степени концентрации. Например, значительный уровень концентрация наблюдается у профессиональных участников рынка ценных бумаг: примерно 82\% финансовых активов обладают 9\% участников фондового рынка [10].

На начало 2020 года число профессиональных участников рынка ценных бумаг несколько уменьшилось по сравнению с аналогичным периодом 2019 года, что обусловлено происходящими процессами централизации капитала, а также усилением контроля макрорегулятора за деятельности брокерских компаний. На рисунке 1 отражена структура профессиональных участников отечественного рынка ценных бумаг.

Развитие рынка ценных бумаг в настоящее время представляется насущной необходимостью, поскольку от уровня его капитализации зависит место России в глобальном мировом 


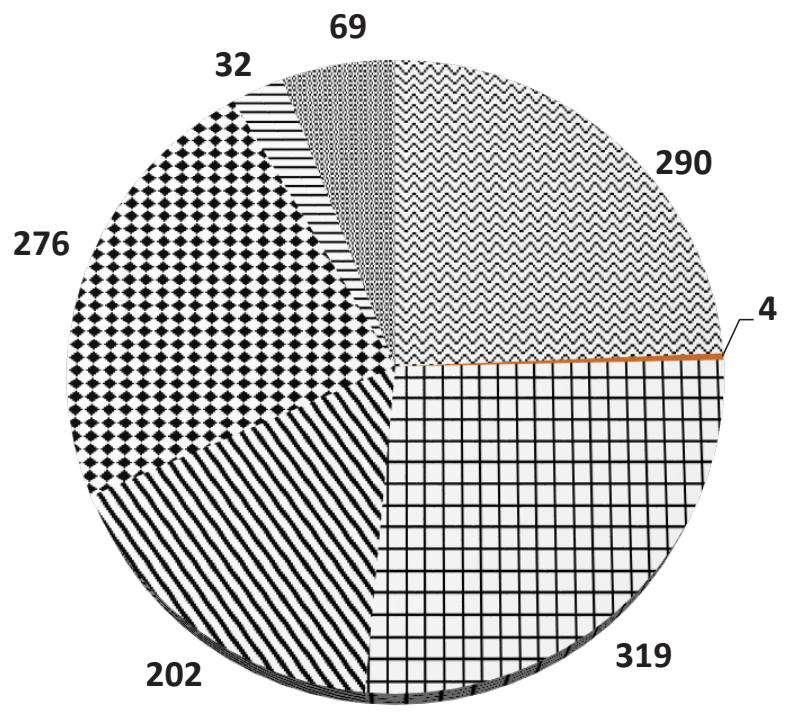

\author{
$\approx$ брокеры \\ - форекс-дилеров \\ Г дилеры \\ мдоверительные \\ управляющие \\ - депозитарии \\ 三регистраторы \\ инвестиционные \\ советники
}

\footnotetext{
Рисунок 1. Количество действующих профессиональных участников рынка ценных бумаг по видам деятельности на 01.01.2020, шт.

Источник: составлено авторами на основе отчета Банка России [11]
}

сообществе [8]. Инвестиционные ресурсы, аккумулированные и перераспределяемые с помощью рынка ценных бумаг, выполняют задачу не только простого воспроизводства основного капитала, но и выступают драйвером формирования новых передовых производств, что обеспечивает экономическую безопасность страны. Именно поэтому необходимо вовлечение все большего числа разнообразных инвесторов, которые имея даже незначительные свободные ресурсы, могут аккумулировать на рынке существенный объем капитала [7]. Инвестиционные компания как профессиональные участники рынка ценных бумаг способствуют реализации трансмиссионного механизма трансформации сбережений в инвестиции, и в этом смысле их роль трудно переоценить.

Особенно это касается мелких и средних инвесторов, чьи временно свободные денежные средства концентрируются инвестиционными компаниями, с целью их вложения в финансовые активы. Следует еще подчеркнуть тот факт, что инвестиционные компании выполняют функцию посредников на фондовом рынке, первоначально привлекая, а затем размещая инвестиционные ресурсы [13]. Таким образом, посредством инвестиционных компаний осуществляется фондирование нуждающихся предприятий, источником которого выступают финансовые ресурсы стабильно развивающихся фирм и организаций.
Слабой стороной национального фондового рынка считаются маленькая величина финансовых активов некредитных финансовых структур в условиях доминировании институтов банковской сферы, которая в текущее время не может предоставить необходимый объем кредитования, так нужный предприятиям реального сектора экономики.

Нарастающая экономическая дестабилизация, вызванная пандемией, не обошла стороной и финансовый рынок, и его профессиональных участников, в частности. Рынок ценных бумаг по своему экономическому содержанию представляет собой достаточно неустойчивую структуру, которой в большей степени свойственно неравновесие и волатильность. Факторы, способные повлиять на формирование инвестиционной стратегии участников рынка ценных бумаг можно подразделить на качественные и количественные. Среди качественных факторов можно выделить человеческий капитал участника рынка ценных бумаг, профессионализм руководства и иные. К количественным показателям относятся курсы валют, динамика агрегированных макроэкономических индексов, динамика индекса потребительских цен [5].

Существует еще один фактор, создающий существенные трудности в процессе функционирования инвестиционных компаний, а именно высокая концентрированность рынка по операциям с ценными бумагами определенных эми- 
тентов. Лидирующими по сумме совершаемых торговых операций являются голубые фишки, в особенности ценные бумаги нефтедобывающих компаний. Такая узость инвестиционных устремлений большей части инвесторов снижает возможности брокеров по извлечению прибыли.

В условиях пандемии параметры социальноэкономического развития национальной эконо- мики сильно ухудшились. В соответствии с прогнозом НИУ ВШЭ (см. рисунки 2 и 3), динамика реальных располагаемых доходов населения в течение последующих лет будет иметь отрицательные значения, что незамедлительно скажется и на показателях прибыльности и рентабельности деятельности инвестиционных компаний, сократив их число.

В подобных условиях жесткой конкуренции

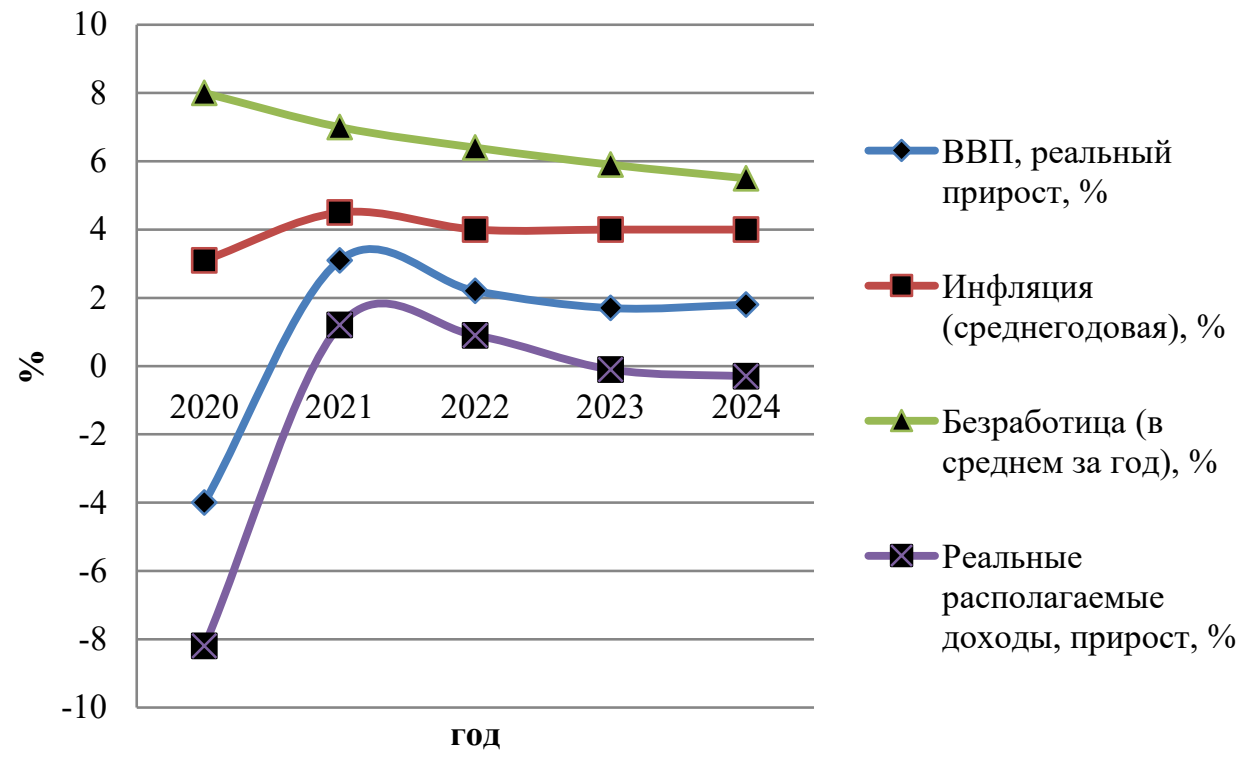

Рисунок 2. Сценарный прогноз макроэкономической динамики и доходов населения до 2024 г., сценарий «Базовый»

Источник: составлено авторами на основе отчета НИУ ВШЭ [12]

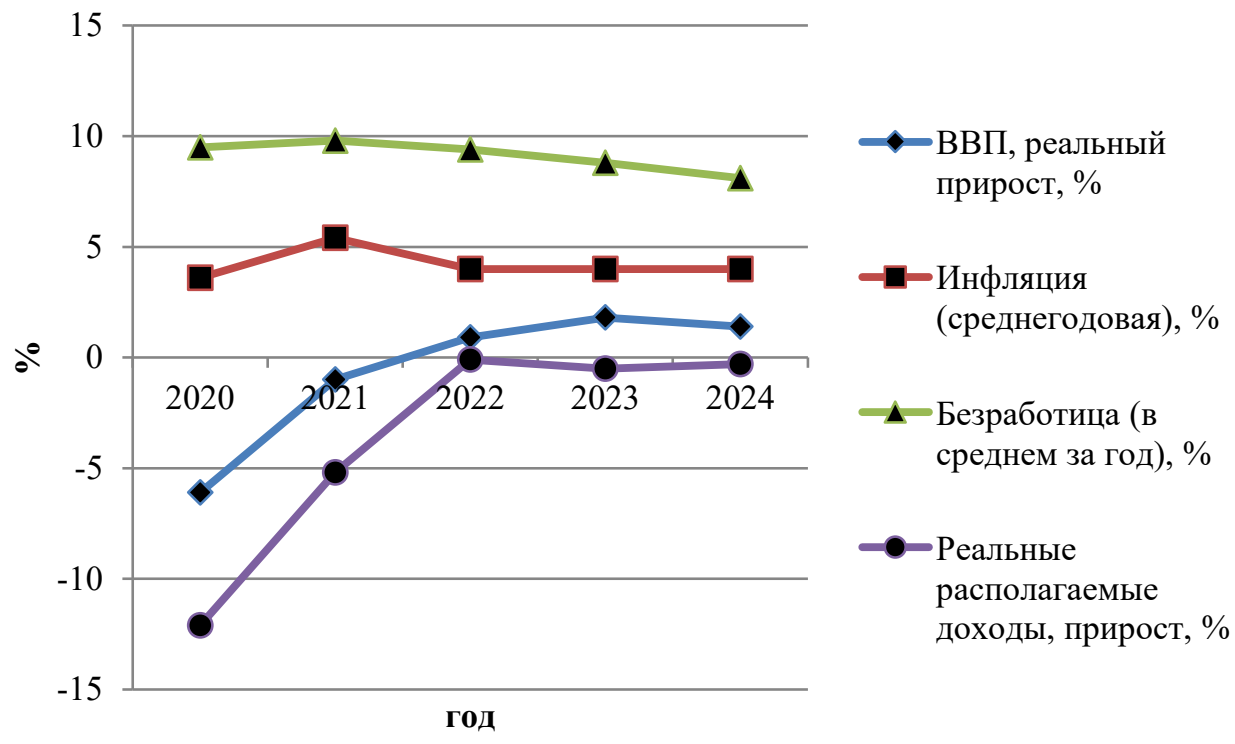

Рисунок 3. Сценарный прогноз макроэкономической динамики и доходов населения до 2024 г., сценарий «Пессимистический» 
на финансовом рынке и неоднозначных прогнозах развития национальной экономики, обеспечение стабильного роста компании возможно только при создании новых конкурентных преимуществ, одним из которых является цифровая трансформация бизнеса.

Участники финансового рынка активно используют в своей деятельности цифровые технологии [6], которые не предполагают материального перемещения и потребления ценностей, информационные ресурсы накапливаются, перерабатываются, их оборот и учет лежит в основе цифрового трансформационного процесса.

Добавленная стоимость на современном этапе зачастую создается в процессе сбора, обработки и предоставления информации, формируя совершенно новые модели посреднического бизнеса. Данные модели, выстроенные на экспоненциальном росте конкурентных преимуществ компании, сводятся к увеличению числа уникальных финансовых продуктов, росте операционной эффективности и создании эксклюзивных клиентских сервисов. Робоэдвайзинг, смарт-контракты и многие другие инновации позволяют брокерским компаниям занимать первые места в рейтингах по объему торговых операций, числу клиентов.

Цифровизация затронула структуру потребностей покупателей финансовых услуг. Их требования к скорости совершаемых операций, качеству и удобству клиентских сервисов кратно возросли. Финансовые организации в таких условиях вынуждены не только участвовать в конкурентной борьбе с другими поставщиками финансовых услуг, но и с потребителями, проактивно внедряя передовые технологии в свой бизнес.

В целях предотвращения и устранения угроз экономической безопасности на фондовом рынке следует рассмотреть ряд мероприятий:

- проведение регулярного анализа состояния фондового рынка с помощью индикаторов для своевременного обнаружения признаков нестабильности на рынке ценных бумаг;

- обеспечение надёжной системы полной ликвидации и предотвращения технологических сбоев на фондовом рынке;

- проводить мониторинг международных финансовых рынков для обеспечения точного прогноза спекулятивных операций в целях предотвратить дестабилизацию национальной экономики;

- установить пределы участия нерезидентов в капитале российских организаций;

- организовать информационную открытость и защиту прав и интересов инвесторов.

Ориентируясь на предложенные мероприятия по предотвращению угроз, можно сделать вывод, что экономическая безопасность фондового рынка зависит от устойчивости и конкурентоспособности экономики, доверия инвесторов, профилактики и противодействия преступности в сфере функционирования рынка ценных бумаг.

\section{Библиографический список}

1. Анесяни Ю.С. Региональный рынок ценных бумаг: проблемы и перспективы развития // Новые технологии.-2011.- Вып. 4.- С. 132-146.

2. Берзон Н. И. Рынок ценных бумаг: учебник. Изд-во: Москва-Юрайт, 2015 год.- С.412.

3. Берзон Н.И., Милицкова Т. М. Детерминанты доходности рублевых корпоративных облигаций // Фондовый рынок. - 2013. - № 16 (544) - С. 84-105.

4. Игнатова Т. В. Роль рынка ценных бумаг в обеспечении эффективного развития региональной финансовой системы // Финансы и кредит. - 2014. - 350 с.

5. овалев П. П. Банковский риск-менеджмент / П. П. Ковалев. М.: ИНФРА-М, 2014. - 320с.

6. Коновалова М.Е., Михайлов А. М., Кузьмина О.Ю. Прогнозирование развития фондовых рынков в условиях становления цифровой экономики //Вестник Самарского экономического университета. 2018. № 11(169). С. 13-19.

7. Миркин Я.М. Рынок ценных бумаг России: воздействие фундаментальных факторов, прогноз и политика развития / Я. М. Миркин. М.: Альпина Паблишер, 2012.-С. 76-78.

8. Михайлов А.М., Искандаров Т. С., Городнов В.А. Роль фондового рынка в финансировании экономики РФ // Экономические науки. 2019. № 173. С. 22-25.

9. Михайлов А.М., Мишина М. С. Анализ состояния и проблемы развития российского рынка ценных бумаг // Экономические науки. 2020. № 187. С. 7-10.

10. Сарычева М. Брокерские клиенты разошлись по банкам // «Коммерсантъ».-26.03.2019. - № 52.- С. 8. 
11. Статистический обзор за 2019 год. - 2019.- C 26. Центральный банк Российской Федерации. - URL: http:// www.cbr.ru/content/document/file/108036/stat_lic_2019.pdf (дата обращения: 22.10.2020).

12. Сценарный прогноз макроэкономической динамики и доходов населения до 2024 г. / Центр развития НИУ ВШЭ.- URL: https://dcenter.hse.ru/ (дата обращения 22.10.2020).

13. Bernanke, Ben S. and Kenneth N. Kuttner. "What Explains the Stock Market's Reaction to Federal Reserve Policy?" // Journal of Finance, 2005, 60 (3), pp. 1221-1257.

14. Engsted T., Tanggaard C. The Relation Between Asset Returns and Inflation at Short and Long Horizons // Journal of International Financial Markets, Institutions and Money.-2002. - T. 12.- pp. 101-118.

15. Feldstein M. Inflation and the Stock Market // The American Economic review. - 1980. - 5: T. 70.- Pp. $839-847$.

16. Hayo B. u Kutan A. M. The Impact of News, Oil Prices, and International Spillovers on Russian Financial Markets // Center for European Integration Studies, Working Paper.- 2002.- P. 20. 